\title{
Molecular Docking Study and ADMET Profile: Manipulation of Angiotensin II Pathophysiology in COVID-19 by Potentilla Reptans Root Compounds
}

\author{
Ayesheh Enayati \\ Golestan University of Medical Sciences \\ Hassan Mirzaei \\ Golestan University of Medical Sciences \\ Vahid Khori \\ Golestan University of Medical Sciences \\ Ali Jabbari \\ Golestan University of Medical Sciences \\ Aref Salehi \\ Golestan University of Medical Sciences \\ Alireza Soltani ( $\square$ alirezasoltaniiii21@gmail.com ) \\ Golestan University of Medical Sciences
}

\section{Research Article}

Keywords: COVID-19, Potentilla reptans, Angiotensin II, Molecular docking simulation, ADMET.

Posted Date: December 30th, 2021

DOl: https://doi.org/10.21203/rs.3.rs-1120002/v1

License: @ (1) This work is licensed under a Creative Commons Attribution 4.0 International License. Read Full License 


\section{Abstract}

In the novel SARS-CoV-2 (COVID-19) as a global emergency event, the main reason of the cardiac injury from COVID-19 is angiotensinconverting enzyme 2 (ACE2) targeting in SARS-CoV-2 infection. The inhibition of ACE2 induces an increase in the angiotensin II (Ang II) and the angiotensin II receptor type 1 (AT1R) leading to impaired cardiac function or cardiac inflammatory responses. The ethyl acetate fraction of Potentilla reptans $\mathrm{L}$. root can rescue heart dysfunction, oxidative stress, cardiac arrhythmias and apoptosis. Therefore, isolated components of $P$. reptans evaluated to identify natural anti-SARS-CoV-2 agents via molecular docking.

In silico molecular docking study were carried out using the Auto Dock software on the isolated compounds of Potentilla reptans root. The protein targets of selective ACE and others obtained from Protein Data Bank (PDB). The best binding pose between amino acid residues involved in active site of the targets and compounds was discovered via molecular docking. Furthermore, ADMET properties of the compounds were evaluated.

The triterpenoids of $P$. reptans showed more ACE inhibitory potential than catechin in both domains. They were selective on the nACE domain, especially compound 5 . Also, the compound $5 \& 6$ had the highest binding affinity toward active site of nACE, CACE, AT1R, ACE2, and TNF-a receptors. Meanwhile, compound 3 showed more activity to inhibit TXA2. Drug likeness and ADMET analysis showed that the compounds passed the criteria of drug likeness and Lipinski rules. The current study depicted that $P$. reptans root showed cardioprotective effect in COVID-19 infection and manipulation of angiotensin Il-induced side effects.

\section{Introduction}

A novel coronavirus (SARS-CoV-2, COVID-19) has caused a great threat to the public healthcare systems and international concern in the world [1-4]. This virus affected seriously endangers human health by causing susceptibility, disease severity, various mutations and high mortality $[5,6]$. As of now, there is not exact conventional medications for the SARS-CoV-2 treatment [5]. It seems that there are several mechanisms involved in SARS-CoV-2 infection in different organs including lung, heart, kidney, and brain [2, 7]. The main target of SARS-CoV-2 propagates is the angiotensin-converting enzyme 2 (ACE2) receptor and renin-angiotensin system (RAS) of host as a vehicle to entry human cells and viral replication [8]. However, SARS-CoV-2 exhibits cardiac dysfunctions (owing to ACE2 abundant in cardiac tissue) including acute myocardial injury, hypokalemia, arrhythmia, myocarditis, and sudden cardiac death [8-12]. At that point, there is a specific attention to manage ACE2 expression or COVID-19 cardiac adverse and its associated targets such as cardiac inflammatory, Ang II induction, cardiac arrhythmia signaling and oxidative stress.

Viral binding to ACE2 leads to ACE2 shedding and an accumulation of Ang II and the angiotensin II receptor type 1 (AT1R), thereby causing an incidence of vasoconstriction, fibrosis, arrhythmogenesis, hypertrophy, proliferation, oxidative stress, cardiac dysfunction and myocardium sensitization $[8,13,14]$. On the other hand, there is the relationship between elevated ACE2 and some cardiac comorbidities such as heart failure, secondary hypertension, coronary artery disease, and cardiomyopathies, which may increase COVID-19 susceptibility and severity [8]. Likewise, angiotensin-I converting enzyme (ACE) inhibitors such as captopril, enalapril, and lisinopril are used to management of COVID-19 [15]. Owing to the non-selectivity of applied ACE inhibitors, they cause some side effects via associated dysregulatory of bradykinin in the patients [16].

The many previous studies have indicated medicinal plants and natural products exert beneficial effects in treatment of COVID-19 [1719], and also, they demonstrated the hopeful ACE inhibitory activity [16]. In this perspective, a growing body of evidence indicates that Potentilla reptans $\mathrm{L}$. (Rosaceae) can rescue heart dysfunction, oxidative stress, cardiac arrhythmias and apoptosis through inhibiting ROS, glucocorticoid regulated kinase-1 (SGK1), glycogen synthase kinase $3 \beta$ (GSK-3 $\beta$ ), BAX and caspase3 regards to increasing Nrf2, SOD, CAT, NO, BCl-2 and improving cardiac hemodynamic function [20-23].

To the best our knowledge, $P$. reptans, as a natural cardioprotective agent may be a promising complementary candidate of COVID-19 for warrant therapeutic intention of ACE2 targeting-COVID-19-induced cardiac adverse. Therefore, we aimed to evaluate isolated components of $P$. reptans to identify natural anti-SARS-CoV-2 agents via molecular docking pointing the selective ACE inhibition and some properties including physicochemical, absorption, distribution, metabolism, excretion, and toxicity (ADMET).

\section{Material And Methods}

Molecular docking 
In this study, the anti-SARS-CoV-2 potential and the plausible selective-ACE inhibition (CACE or nACE domains) potential of $P$. reptans root compounds (Figure 1) were investigated by in silico docking software Auto Dock (4.2) [24] on nACE-inhibition (PDB IDs: 6F9Vand 6EN5) and CACE-inhibition (PDB IDs: 1UZF, 20C2, 6F9T and 6F9U) complexes [16]. Also, anti-inflammatory (PDB ID: 3KK6 and 2AZ5) and antithrombotic (PDB ID: 6IIU) effects of compounds were performed by molecular docking.

The 3D structure of targets obtained from PubChem database as following: the human testicular angiotensin I-converting enzyme (CACE) (PDB ID: 1UZF), crystal structure of human angiotensin receptor in complex with inverse agonist olmesartan (AT1R) (PDB ID: 4ZUD), crystal structure of human angiotensin-1 converting enzyme N-domain in complex with sampatrilat (nACE) (PDB ID: 6F9V), crystal structure of human testis angiotensin-1 converting enzyme in complex with sampatrilat (CACE) (PDB ID: 6F9T), human testis Angiotensin-1 converting enzyme (CACE) (PDB ID: 6F9U), structure of testis ACE with RXPA380 (CACE) (PDB ID: 20C2), crystal structure of the angiotensin-1 converting enzyme N-domain in complex with a diprolyl inhibitor (nACE) (PDB ID: 6EN5), structure of human angiotensin receptor inhibitor (AT1RI) (PDB ID: 4YAY), inhibitor bond human angiotensin converting enzyme-related carboxypeptidase (ACE2) (PDB ID: 1R4L), crystal structure of cyclooxygenase-1 in complex with celecoxib (COX-1) (PDB ID: 3KK6), crystal structure of the human thromboxane A2 receptor bond to ramatroban (TXA2) (PDB ID: 6IIU), crystal structure of TNF-alpha (TNF-a) (PDB ID: 2AZ5).

The docking was performed on the target proteins, which were removed water molecules/non-polar hydrogen atoms and added polar hydrogens/kollman charges. Lamarckian genetic algorithm (GA) was used for local search method with a grid box of $60 \times 60 \times 60$ and point spacing of $0.375 \AA$ that was set for creating of autogrid module $[25,26] .150$ GA runs were accomplished for each docking. Maestro 11.0 Schrodinger suit and Discovery Studio Visualizer software was applied for visualization of 2D and 3D presentation.

\section{Ligand Preparation}

The 3D structure of each phytochemical (Figure 1) was retrieved from PubChem database in SDF format and then converted into PDB format using Open Babel software. Chem3D software was utilized for energy minimization of ligands. Captopril, an ACE inhibitor not selective inhibitor, was used as a control.

\section{Drug Likeness And Admet Prediction}

Efficacy and safety profile of the mentioned natural compounds including absorption, distribution, metabolism, excretion and toxicity (ADMET) and their pharmacokinetics were predicted using admetSAR database [27] and swissADME [28]. Furthermore, we investigated topological polar surface area (TPSA) as an important descriptor predicting oral bioavailability and absorption of the compounds. Also, the compound effects on permeability of blood-brain barrier (BBB), inhibition of cytochrome P450 (CYP3A4, CYP2C9 and CYP2D6), AMES toxicity and carcinogenicity were evaluated.

\section{Results}

\section{Molecular docking}

According to Table 1, the triterpenoids of $P$. reptans showed more ACE inhibitory potential than catechin in both domains. Also, they were selective on the nACE domain based on their lower binding energies on $6 \mathrm{~F} 9 \mathrm{~V}$ and $6 \mathrm{EN} 5$ targets, especially compound $\mathbf{5}$ had the lowest binding energy. Between assessed-PDB IDs of CACE domain, the triterpenoids revealed their lower binding energy in the binding pocket of 6F9U, mainly compound $6(-10.2 \mathrm{kcal} / \mathrm{mol})$, and also, it acted as more selective for CACE with lower binding energy for $6 \mathrm{~F} 9 \mathrm{~T}$ and $20 \mathrm{C} 2$ (as cACE domain complexes). 
Table 1

Molecular docking simulation results for the compounds and receptors.

\begin{tabular}{|c|c|c|c|c|c|c|c|c|c|c|c|c|}
\hline \multirow[t]{3}{*}{ Compound } & \multicolumn{12}{|c|}{ Binding Energy (kcal/mol) } \\
\hline & \multicolumn{12}{|c|}{ PDB ID: } \\
\hline & $\begin{array}{l}\text { 1UZF } \\
\text { (cACE) }\end{array}$ & $\begin{array}{l}20 \mathrm{C} 2 \\
\text { (CACE) }\end{array}$ & $\begin{array}{l}6 \mathrm{~F} 9 \mathrm{~T} \\
\text { (cACE) }\end{array}$ & $\begin{array}{l}6 \mathrm{~F} 9 \mathrm{U} \\
\text { (cACE) }\end{array}$ & $\begin{array}{l}\text { 6F9V } \\
\text { (nACE) }\end{array}$ & $\begin{array}{l}\text { 6EN5 } \\
\text { (nACE) }\end{array}$ & $\begin{array}{l}\text { 4YAY } \\
\text { (AT1RI) }\end{array}$ & $\begin{array}{l}\text { 4ZUD } \\
\text { (AT1R) }\end{array}$ & $\begin{array}{l}\text { 1R4L } \\
\text { (ACE2) }\end{array}$ & $\begin{array}{l}3 \mathrm{KK} 6 \\
\text { (COX- } \\
1)\end{array}$ & $\begin{array}{l}6 I I U \\
\text { (TXA2) }\end{array}$ & $\begin{array}{l}2 A Z 5 \\
\text { (TNF- } \\
\text { a) }\end{array}$ \\
\hline Captopril & -7.6 & -7.0 & -7.1 & -7.4 & -7.3 & -7.1 & -7.1 & -7.2 & -7.6 & -7.4 & -7.3 & -7.4 \\
\hline Catechin & -7.3 & -7.2 & -7.4 & -7.7 & -7.5 & -7.6 & -7.3 & -7.3 & -7.8 & -7.8 & -7.5 & -7.5 \\
\hline 1 & -7.6 & -7.8 & -8.2 & -8.7 & -8.8 & -8.3 & -7.7 & -7.7 & -8.7 & -7.3 & -8.0 & -7.9 \\
\hline 2 & -7.8 & -7.6 & -7.9 & -9.5 & -9.5 & -9.1 & -7.9 & -7.8 & -9.8 & -7.1 & -8.3 & -8.1 \\
\hline 3 & -8.1 & -8.7 & -8.6 & -9.2 & -9.4 & -9.2 & -8.1 & -8.0 & -9.4 & -7.7 & -9.2 & -8.2 \\
\hline 4 & -8.0 & -8.5 & -8.8 & -9.0 & -9.7 & -9.7 & -8.6 & -8.2 & -9.7 & -7.5 & -8.9 & -8.5 \\
\hline 5 & -8.2 & -8.3 & -8.9 & -9.6 & -10.4 & -9.8 & -8.4 & -9.4 & -9.9 & -8.3 & -8.1 & -8.3 \\
\hline 6 & -7.7 & -9.3 & -9.6 & -10.2 & -9.6 & -9.6 & -9.1 & -8.6 & -9.5 & -6.3 & -8.8 & -8.6 \\
\hline
\end{tabular}

In addition, the results indicated that $P$. reptans root compounds are ACE inhibitor regards to the binding energy of ATR-inhibitor complexes 4 YAY and 4ZUD, but compounds 5 and $\mathbf{6}$ showed suitable energy for ATR inhibition and acted as angiotensin receptor blocker (ARB). In ACE2 inhibitory investigation, triterpenoids were effective in the binding pocket of 1R4L protein especially compounds $\mathbf{5}$ and $\mathbf{2}$ (Table 1). In general, compounds $\mathbf{5}$ and $\mathbf{6}$ were more active in the inhibition of ACE, ACE2 and AT1R with their hydroxyl groups and electron donor-OMe substitution, thereby a preparation condition of interaction with the target $\mathrm{Zn}^{2+}$ ion.

In the present study, the compound 5 interacted with the 6F9V target in its active sites Cys330, Leu139, Phe490, Trp257, Phe435, Tyr498, Tyr501, Ala332, Tyr122 and Phe505 through hydrophobic interaction (Fig. 2A). Its polar interaction represented with residues Thr144, Arg350, Asp255, Lys489, His491, Ser260, Glu262, Asp393, Asp354, Glu431, and Ser504. Furthermore, hydroxyl and carbonyl groups of the compound 5 formed 11 hydrogen bond with the amino acid residues Asp415, Asn277, His353, Cys352, Ala354, Thr372, Asp377 and Cys370 at the distances of 2.67, 3.04, 1.91, 2.62, 3.15, 1.78, 2.57, 2.77, 2.75, 2.62, and 2.66 A, respectively (Fig. 2A). on the other hand, compound 5 interacted with the $\mathrm{Zn}^{2+}$ ion as essential element to binding the $6 \mathrm{~F} 9 \mathrm{~V}$ target.

Figure 2B illustrated hydrophobic interactions between the amino acid residues of target (6EN5) and compound $\mathbf{5}$. In addition, the polar interactions with amino acid residues Asp140, Asp354, Arg350, Gln355, Glu389, Asp393, Ser504, Ser357, Thr358, His361, Lys432, His491, and Lys489 with compound $\mathbf{5}$ were indicated, that Thr358 interaction is important in nACE selectivity of compound $\mathbf{5}$ [16]. Furthermore, the compound 5 formed 8 hydrogen bonds with residues His331, Thr144, His491, Tyr498, Tyr501, Gln259 and Ser260 of 6 EN5 target at 2.85, 2.96, 2.33, 1.89, 2.77, 2.23, 2.53 and $2.74 \AA$, respectively (Supplementary material Figure S1). As illustrated in figure $2 \mathrm{C}-\mathrm{E}$, the compound 6 revealed selective cACE domain in the active site of targets (6F9U, 6F9T and 20C2) through polar, hydrogen bond or hydrophobic interactions between important residues of targets with its hydroxyl, carbonyl and methoxyl groups (Supplementary material Figure S2, S3, S4). Also, compound 6 and zinc atom of $6 \mathrm{~F} 9 \mathrm{U}$ interacted at $1.7 \AA$.

In the AT1R inhibitory analysis, compound $\mathbf{5}$ and $\mathbf{6}$ showed the lowest bonding energy in 4ZUD and 4YAY, respectively (Fig. 3A-B, Supplementary material Figure S5, S6). In addition, the result of this study indicated the ACE2 inhibitory energy for compound $\mathbf{5}$ is -9.9 $\mathrm{kcal} / \mathrm{mol}$ in the interaction with key amino acid residues of $1 \mathrm{R} 4 \mathrm{~L}$ and binding to $\mathrm{Zn}^{2+}$ ion at a distance of $2.9 \AA$ (Fig. 3C, Table 1 , Supplementary material Figure S7).

As shown Table1, the compounds did not significantly inhibit COX-1. Compound 6 showed an inhibitory effect, more than other triterpenoids, on TNF-a (Fig. 4A, Supplementary material Figure S8). In TXA2 inhibition compound 3 exerted binding affinity with residues Trp209 and Arg295 through its hydroxyl groups at 2.72 and $2.06 \AA$ A, respectively (Fig. 4B, Supplementary material Figure S9).

\section{Drug Likeness And Admet Prediction}

Page $4 / 13$ 
Pharmacokinetic and toxicity properties of compounds were determined. The results of predicted ADMET properties of compounds and toxicity profiles presented in Table 2 .

Table 2

Drug-likeness properties of compounds.

\begin{tabular}{|lllllllll|}
\hline Compound & MW & Log $S$ & C log P & HBA & HBD & NRB & MR & TPSA \\
\hline Ref. & - & $>-4$ & $<=5$ & $<=10$ & $<=5$ & $<=10$ & $40-130$ & $<140$ \\
\hline $\mathbf{1}$ & 650 & -3.71 & 3.2 & 10 & 7 & 4 & 171 & 177 \\
\hline $\mathbf{3}$ & 650 & -3.86 & 2.43 & 10 & 7 & 4 & 171 & 177 \\
\hline $\mathbf{3}$ & 648 & -3.76 & 3.26 & 10 & 6 & 4 & 170 & 173 \\
\hline $\mathbf{5}$ & 650 & -3.89 & 3.22 & 10 & 7 & 4 & 171 & 177 \\
\hline $\mathbf{6}$ & 696 & -3.61 & 2.06 & 12 & 8 & 6 & 178 & 206 \\
\hline Catechin & 290 & -2.73 & 1.34 & 6 & 5 & 1 & 74 & 285 \\
\hline Captopril & 217 & -0.06 & 0.27 & 4 & 1 & 4 & 60 & 57 \\
\hline
\end{tabular}

HBA: Number of hydrogen bonds acceptors; HBD: Number of hydrogen bond donors; Log S: Logarithm of water solubility; C Log P: Calculated logarithm of compound partition coefficient between n-octanol and water; MR: Molecular refractivity; MW: molecular weight; NRB: Number of rotatable bonds; TPSA: Topological polar surface area.

To get an insight about the compliance of compounds with Lipinski's Rule of Five, the compounds screened for more analysis. Notably, most compounds passed Lipinski rule and did not show any violation of standardized Lipinski rule of five. Values of calculated solubility of compounds ranging from -3.08 to -3.89 indicating moderate solubility of compounds, and also calculated Log P indicated between 1.29 and 3.26. Moreover, molecular weight was more than 500 Dalton, number of hydrogen bond donors were more than 5 , while number of $\mathrm{H}$-acceptors of compound $\mathbf{5}$ and $\mathbf{6}$ exhibited violation of Lipinski rule and others obey Lipinski rule.

Molar refractivity of all compounds were more than 130. According to data presented in Table 2 and 3 pharmacokinetic parameters and ADMET profiles (absorption, distribution, metabolism, excretion, and toxicity) evaluated to predict the toxicity parameters of the compounds. However, all the compounds are following the criteria of drug likeness rules. All the compounds indicated good absorption and permeability demonstrating moderate absorption. Evaluation of two key ADMET descriptor like Human Intestinal Absorption (HIA) and blood brain barrier (BBB) exhibited appropriate profiles. Furthermore, the obtained results revealed that all of the compounds were non-inhibitors of CYP450 enzymes (3A4, 2D6, and 2C9) acting as an effective factor in drug metabolism. Additionally, most compounds were non-carcinogenic, non-hepatotoxicity and non-AMES toxicity. 
Table 3

ADMET (absorption, distribution, metabolism, excretion and toxicity) profile of compounds.

\begin{tabular}{|c|c|c|c|c|c|c|c|c|c|c|c|}
\hline Compound & BBB & HIA & Caco2 & $P-G I$ & CYP450-2C9 & CYP450-2D6 & CYP450-3A4 & AMES & CIG & HPT & $\mathrm{AOC}$ \\
\hline Ref. & - & - & - & No & No & No & No & No & No & No & - \\
\hline 1 & No & Yes & No & Yes & No & No & No & No & No & No & 3.1 \\
\hline 2 & No & Yes & No & Yes & No & No & No & No & No & No & 3.1 \\
\hline 3 & No & Yes & No & Yes & No & No & No & No & No & No & 3.2 \\
\hline 4 & No & Yes & No & Yes & No & No & No & No & No & No & 3.5 \\
\hline 5 & No & Yes & No & Yes & No & No & No & No & No & No & 3.0 \\
\hline 6 & No & No & No & Yes & No & No & No & No & No & No & 3.3 \\
\hline Catechin & No & Yes & No & No & No & No & No & No & No & No & 2.0 \\
\hline Captopril & Yes & Yes & No & No & Yes & No & No & No & No & No & 1.8 \\
\hline
\end{tabular}

\section{Discussion}

The previous studies established cardioprotective effects of $P$. reptans compounds in docking and animal experimental studies due to

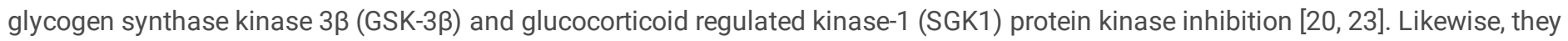
demonstrated an ischemic preconditioning property via antioxidant activity, nitric oxide release, activating Nrf2 pathway, and decreasing apoptotic markers in an isolated rat heart ischemia/reperfusion model [22]. Consistent with these data, P. reptans compounds may be applied for cardioprotection in COVID-19 by beneficial cardioprotective effects.

In this study, the isolated triterpenoids of $P$. reptans root showed selective ACE inhibitory effect as well as inhibition of ACE2 and AT1R, especially compound $\mathbf{5}$ and $\mathbf{6}$, compared with catechin (Table $\mathbf{1}$ ). However, it may be explained by hydroxyl groups and electron donor substances in chemical structure of triterpenoids. In addition, the compound $\mathbf{5}$ and $\mathbf{6}$ had the highest binding affinity toward active site of nACE, CACE, AT1R and ACE2 receptors, through -OMe element or hydroxyl groups. Also, their non-covalent (hydrogen bond and hydrophobic) interactions have a significant role in occupation of active site of the targets. Therefore, compound $\mathbf{5}$ and $\mathbf{6}$ can be considered as a potential selective ACE inhibitor by binding to the key amino acid residues in the active site of the targets.

To the best of our knowledge, the selective inhibition of ACE plays a pivotal role in controlling the RAS and kallikrein-kinin system (KKS), thereby normal hydrolyzing of the anti-inflammatory peptide N-acetyl-SDKP and bradykinin by nACE and CACE, respectively. Therefore, selective CACE inhibitors diminish the production of angiotensin-II (AngII), ACE2 and plausible angioedema. On the other hand, selective nACE inhibitors attenuate inflammation and fibrosis of heart, renal and vascular through increasing $\mathrm{N}$-acetyl-SDKP levels [16, 29]. However, selective ACE inhibitors prevent the activity of CACE or nACE domains.

It seems that AT1R and ACE2 inhibitory effects of $P$. reptans triterpenoids (as shown Table 1) can explain their suppressing effects in inflammatory and cardiac fibrosis induced by COVID-19 infection and dysfunction in RAS. It has been reported that Angll induced angiotensin II type-2 receptor (AT2R) and NO production when AT1R blocked and leads to cardioprotection and anti-fibrosis via inhibiting of norepinephrine, MAPK and ERK1/2 along with inducing vasodilation by bradykinin/NO/cGMP cascades [30, 31]. In addition, the previous studies indicated that isolated ingredients of $P$. reptans inhibited cardiac apoptosis via NO release, inhibiting GSK-3 $\beta$ and activating RISK/SAFE pathways in reperfusion injury [23]. On the other hand, AT1R inhibition may upregulate ACE2 levels as important target of SARS-CoV-2 [15], thereby the $P$. reptans compounds can exert a protective role against an increase in ACE2 by their affinity to occupation of ACE2 complex.

In the next step, the current study demonstrated that compounds of $P$. reptans inhibited TXA2 and TNF-a (Table 1) as adverse effects of infection with COVID-19, which can be in line with mentioned properties of compounds and explain by their antioxidant and antiinflammatory or anti-apoptotic effects [22, 23]. Furthermore, the recent study reported that Angll acts similar to inflammatory cytokine and induces hypertrophy, fibrosis, arterial fibrillation and arrhythmia in the heart [31]. Likewise, it can activate numerous kinases such as 
SGK1 that plays a pivotal dual role in the pathogenesis of cardiac arrhythmia, inflammation and remodeling in response to progressive elevated Angll [31,32]. Agreeing with this evidence, ethyl acetate fraction of $P$. reptans exerted inhibitory effects on SGK1 to reduce arrhythmia and cardiac apoptosis in ischemia/reperfusion injury [20,23]. However, Angll and AT1R could cause arterial/ventricular fibrillation, thus, by blocking ACE or AT1R it would be plausible that inhibition of SGK1 to reduce the prolongation of the action potential duration (APD), hypokalemia, and the proarrhythmic effects of Angll [33]. Therefore, Potentilla reptans compounds may be promising candidate as anti-arrhythmic agent for management of ACE2 targeting-COVID-19-induced arrhythmia due to their ACE or AT1R inhibitory properties.

Taken together, isolated substance of ethyl acetate fraction of $P$. reptans root showed cardioprotective effect in COVID-19 infection and manipulation of angiotensin II-induced side effects by molecular docking which can be postulated as new selective ACE inhibitors. Although ethyl acetate fraction of $P$. reptans root showed beneficial pharmacological properties in the management of COVID-19 and its adverse effects, larger preclinical and clinical studies are needed to determine whether the compounds reveal safety and selective ACE that indicated by molecular docking.

\section{Conclusions}

In conclusion, the molecular docking results of present study gave insights into the potential efficacy of triterpenoid compounds from $P$. reptans root against COVID-19 through selective ACE inhibitory effect, AT1R and ACE2 inhibition. Ursane type triterpenoids and catechins of $P$. reptans, especially compound $\mathbf{5}$ and $\mathbf{6}$, seems to contribute to anti-COVID-19 and cardioprotective effects of this plant in the in silico. Our findings indicate that $P$. reptans compounds follow Lipinski rule of five and had good pharmacokinetic properties and ADMET profiles. However, further studies in animal and clinical areas in an enhanced setting, are needed to indicate other promising targets and mechanisms of anti-COVID-19 from Potentilla reptans root ingredients. Finally, it can be a hopeful natural-based approach for demoliting the pathogenesis of COVID-19 and boosted Angll.

\section{Declarations}

\section{Acknowledgments}

This article financially supported by Golestan University of Medical Sciences, Gorgan, Iran (IR.GOUMS.REC.1400.107).

\section{Conflict of interest}

The authors declare that there is no conflict of interest. The authors alone are responsible for the content of the paper.

\section{References}

[1]. Wang C, Horby PW, Hayden FG GG. A novel coronavirus outbreak of global health concern. Lancet. 2020;395(10223):470-3.

[2]. Huang C, Wang Y, Li X, Ren L, Zhao J, Hu Y, Zhang L, Fan G, Xu J, Gu X, Cheng Z. Clinical features of patients infected with 2019 novel coronavirus in Wuhan, China. The lancet. 2020;395(10223):497-506.

[3]. Eftekhari M, Enayati A, Doustimotlagh AH, Farzaei MH, Yosifova Aneva I. Natural Products in Combination Therapy for COVID-19: QT Prolongation and Urgent Guidance. Natural Product Communications. 2021 Sep;16(9):1934578X211032471.

[4]. Eftekhari M, Salehi A, Enayati A. Management of COVID-19 by phytotherapy: A pharmacological viewpoint. Journal of Reports in Pharmaceutical Sciences. 2021 Jan 1;10(1):153.

[5]. Fuzimoto AD, Isidoro $C$. The antiviral and coronavirus-host protein pathways inhibiting properties of herbs and natural compoundsadditional weapons in the fight against the COVID-19 pandemic? J. Tradit. Complement. Med. 2020;10(4):405-19.

[6]. Hajikhani B, Calcagno T, Nasiri MJ, Jamshidi P, Dadashi M, Goudarzi M, Eshraghi AA, FACS, Mirsaeidi M. Olfactory and gustatory dysfunction in COVID-19 patients: A meta-analysis study. Physiol. Rep. 2020;8(18):e14578.

[7]. Kannan SP, Ali PS, Sheeza A, Hemalatha K. COVID-19 (Novel Coronavirus 2019)-recent trends. Eur Rev Med Pharmacol Sci. 2020;24(4):2006-11. 
[8]. Pathangey G, Fadadu PP, Hospodar AR, Abbas AE. Angiotensin-converting enzyme 2 and COVID-19: patients, comorbidities, and therapies. Am J Physiol Lung Cell Mol Physiol. 2021;320(3):L301-30.

[9]. Puelles VG, Lütgehetmann M, Lindenmeyer MT, Sperhake JP, Wong MN, Allweiss L, Chilla S, Heinemann A, Wanner N, Liu S, Braun F. Multiorgan and renal tropism of SARS-CoV-2. N Engl J Med. 2020;383(6):590-2.

[10]. Tavazzi G, Pellegrini C, Maurelli M, Belliato M, Sciutti F, Bottazzi A, Sepe PA, Resasco T, Camporotondo R, Bruno R, Baldanti F. Myocardial localization of coronavirus in COVID-19 cardiogenic shock. Eur J Heart Fail. 2020;22(5):911-5.

[11]. Wichmann D, Sperhake JP, Lütgehetmann M, Steurer S, Edler C, Heinemann A, Heinrich F, Mushumba H, Kniep I, Schröder AS, Burdelski C. Autopsy findings and venous thromboembolism in patients with COVID-19: a prospective cohort study. Ann Intern Med. 2020;173(4):268-77.

[12]. Gupta A, Madhavan MV, Sehgal K, Nair N, Mahajan S, Sehrawat TS, Bikdeli B, Ahluwalia N, Ausiello JC, Wan EY, Freedberg DE. Extrapulmonary manifestations of COVID-19. Nat Med. 2020;26(7):1017-32.

[13]. Bos JM, Hebl VB, Oberg AL, Sun Z, Herman DS, Teekakirikul P, Seidman JG, Seidman CE, Dos Remedios CG, Maleszewski JJ, Schaff HV. Marked up-regulation of ACE2 in hearts of patients with obstructive hypertrophic cardiomyopathy: implications for SARS-CoV-2mediated COVID-19. Mayo Clin Proc. 2020;95: 1354-1368.

[14]. Liu PP, Blet A, Smyth D, Li H. The science underlying COVID-19: implications for the cardiovascular system. Circulation. 2020;142(1):68-78.

[15]. Onweni CL, Zhang YS, Caulfield T, Hopkins CE, Fairweather DL, Freeman WD. ACEI/ARB therapy in COVID-19: The double-edged sword of ACE2 and SARS-CoV-2 viral docking. Critical Care. 2020;24(1):1-3.

[16]. Caballero J. Considerations for Docking of Selective Angiotensin-Converting Enzyme Inhibitors. Molecules. 2020;25(2):295.

[17]. Din M, Ali F, Waris A, Zia F, Ali M. Phytotherapeutic options for the treatment of COVID-19: A concise viewpoint. Phytother Res. $2020 ; 1-7$.

[18]. Hashem-Dabaghian F, Zimi SA, Bahrami M, Latifi SA, Enayati A, Qaraaty M. Effect of Lavender (Lavandula angustifolia L.) syrup on olfactory dysfunction in COVID-19 infection: A pilot controlled clinical trial. Avicenna Journal of Phytomedicine (AJP). 2021;

[19]. Monfared M, Eftekhari M, Enayati A, Sabeti M, Amini MH. COVID-19 disease management from the perspective of Traditional Persian Medicine. Journal of Islamic and Iranian Traditional Medicine (JIITM). 2020;11(1):11-22.

[20]. Enayati A, Salehi A, Alilou M, Stuppner H, Mirzaei H, Omraninava A, Khori V, Yassa N. Six new triterpenoids from the root of Potentilla reptans and their cardioprotective effects in silico. Nat Prod Res. 2021;1-9.

[21]. Enayati A, Khori V, Saeedi Y, Yassa N. Antioxidant activity and cardioprotective effect of Potentilla Reptans L. via ischemic preconditioning (IPC). RJP. 2019;6(1):19-27.

[22]. Enayati A, Yassa N, Mazaheri Z, Rajaei M, Pourabouk M, Ghorghanlu S, Basiri S, Khori V. Cardioprotective and anti-apoptotic effects of Potentilla reptans L. root via Nrf2 pathway in an isolated rat heart ischemia/reperfusion model. Life Sci. 2018; 215:216-26.

[23]. Enayati A, Salehi A, Alilou M, Stuppner H, Polshekan M, Rajaei M, Pourabouk M, Jabbari A, Mazaheri Z, Yassa N, Moheimani HR, Khori V. Potentilla reptans L. Postconditioning Protects Reperfusion Injury Via The RISK/SAFE Pathways in an Isolated Rat Heart. DOI: https://doi.org/10.21203/rs.3.rs-148595/v1

[24]. Morris GM, Huey R, Lindstrom W, Sanner MF, Belew RK, Goodsell DS, Olson AJ. AutoDock4 and AutoDockTools4: Automated docking with selective receptor flexibility. Journal of computational chemistry (J. Comput. Chem.). 2009;30(16):2785-91.

[25]. Mirzaei H, Shokrzadeh M, Emami S. Synthesis, cytotoxic activity and docking study of two indole-chalcone derivatives. Journal of Mazandaran University of Medical Sciences (J. Maz. Univ. Med. Sci.). 2017;27(154):12-25.

[26]. Emami S, Esmaili Z, Dehghan G, Bahmani M, Hashemi SM, Mirzaei H, Shokrzadeh M, Moradi SE. Acetophenone benzoylhydrazones as antioxidant agents: synthesis, in vitro evaluation and structure-activity relationship studies. Food chemistry (Food Chem.). 
[27]. Yang H, Lou C, Sun L, Li J, Cai Y, Wang Z, Li W, Liu G, Tang Y. admetSAR 2.0: web-service for prediction and optimization of chemical ADMET properties. Bioinformatics (Bioinform.). 2019;35(6):1067-9.

[28]. Daina A, Michielin O, Zoete V. SwissADME: a free web tool to evaluate pharmacokinetics, drug-likeness and medicinal chemistry friendliness of small molecules. Scientific reports (Sci. Rep.). 2017;7(1):1-3.

[29]. Bernstein KE, Shen XZ, Gonzalez-Villalobos RA, Billet S, Okwan-Duodu D, Ong FS, Fuchs S. Different in vivo functions of the two catalytic domains of angiotensin-converting enzyme (ACE). Current opinion in pharmacology (Curr. Opin. Pharmacol.). 2011;11(2):10511.

[30]. Li Y, Li XH, Yuan H. Angiotensin II type-2 receptor-specific effects on the cardiovascular system. Cardiovascular diagnosis and therapy (Cardiovasc Diagn Ther.). 2012;2(1):56.

[31]. Forrester SJ, Booz GW, Sigmund CD, Coffman TM, Kawai T, Rizzo V, Scalia R, Eguchi S. Angiotensin II signal transduction: an update on mechanisms of physiology and pathophysiology. Physiological reviews (Physiol. Rev.). 2018;98(3):1627-738.

[32]. Gan W, Ren J, Li T, Lv S, Li C, Liu Z, Yang M. The SGK1 inhibitor EMD638683, prevents Angiotensin Il-induced cardiac inflammation and fibrosis by blocking NLRP3 inflammasome activation. Biochimica et Biophysica Acta (BBA)-Molecular Basis of Disease (BBA-MOL BASIS DIS). 2018;1864(1):1-0.

[33]. Goette A, Lendeckel U. Electrophysiological effects of angiotensin II. Part I: signal transduction and basic electrophysiological mechanisms. Europace. 2008;10(2):238-41.

\section{Supplementary Material}

Supplementary material is not available with this version.

\section{Figures}



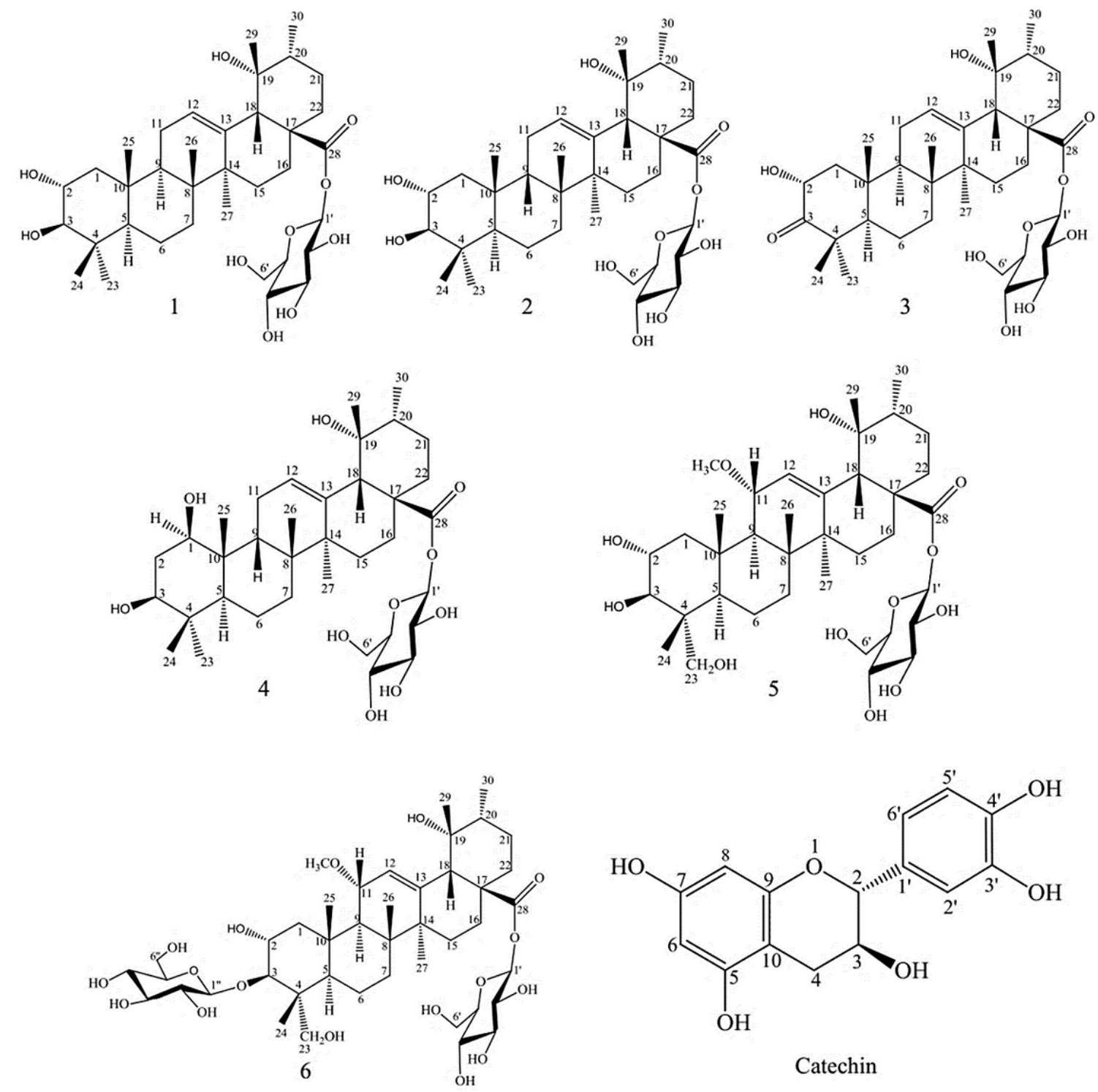

Figure 1

Structures of isolated compounds from $P$. reptans root.

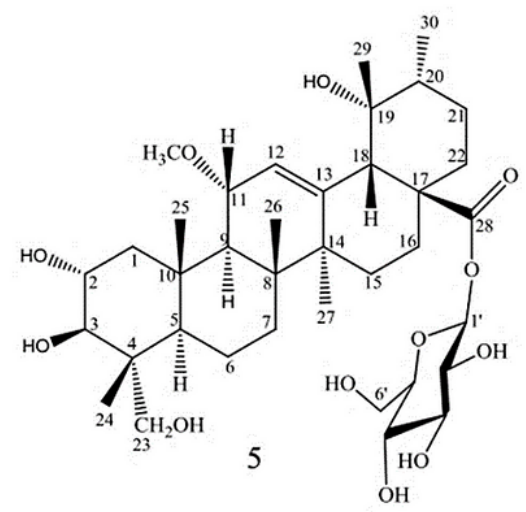<smiles>Oc1cc(O)c2c(c1)OC(c1ccc(O)c(O)c1)[C@H](O)C2</smiles>

Catechin 

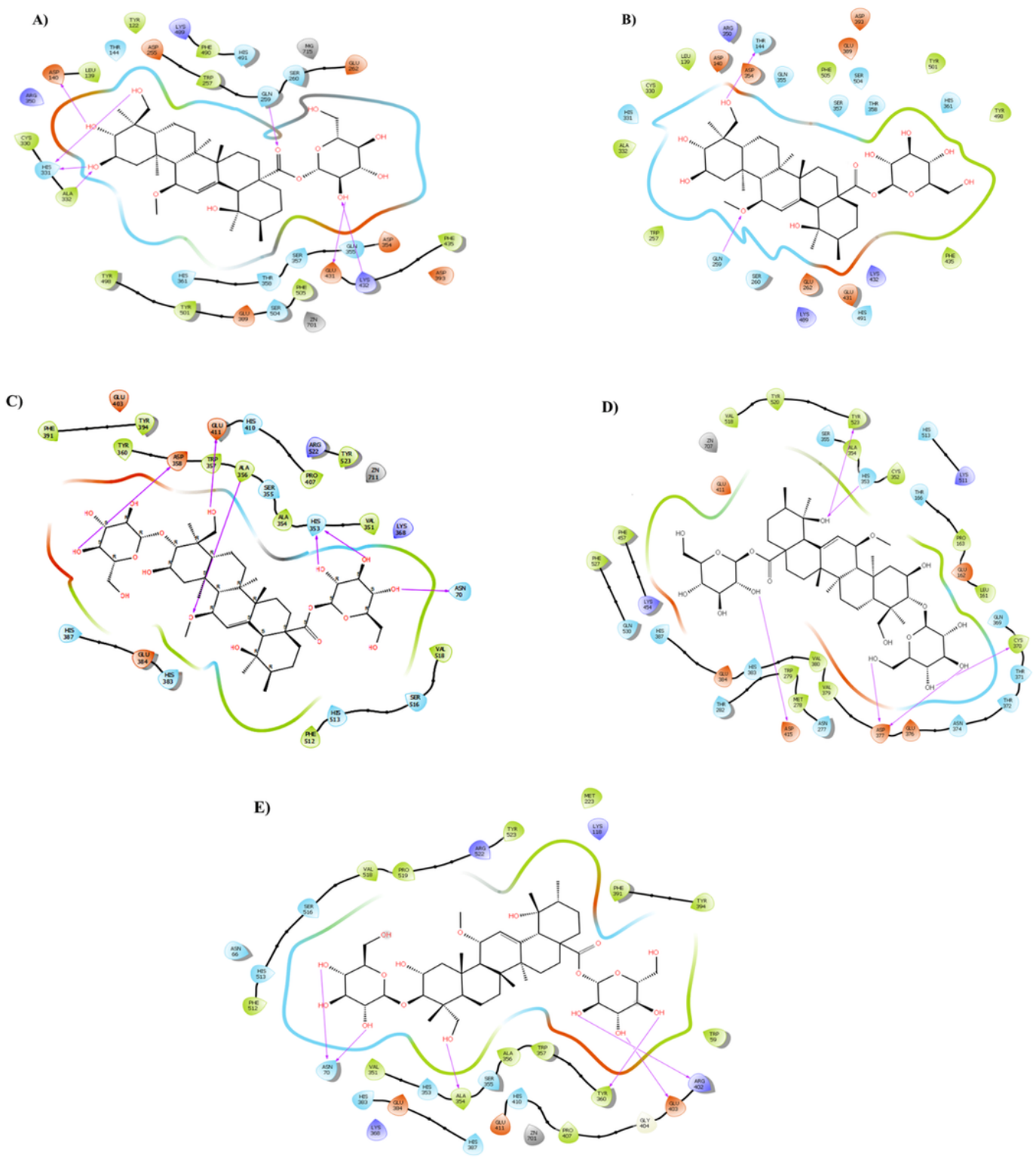

\section{Figure 2}

Presentation of 2D model of interactions between compound 5 (A-B) and compound $\mathbf{6}$ (C-E) on selective ACE domains. A) Compound 5 and nACE (PDB ID:6F9V); B) Compound $\mathbf{5}$ and nACE (PDB ID:6EN5); C) Compound $\mathbf{6}$ and CACE (PDB ID: 6F9T); D) Compound 6 and CACE (PDB ID: 6F9U); E) Compound 6 and CACE (PDB ID: 20C2). 

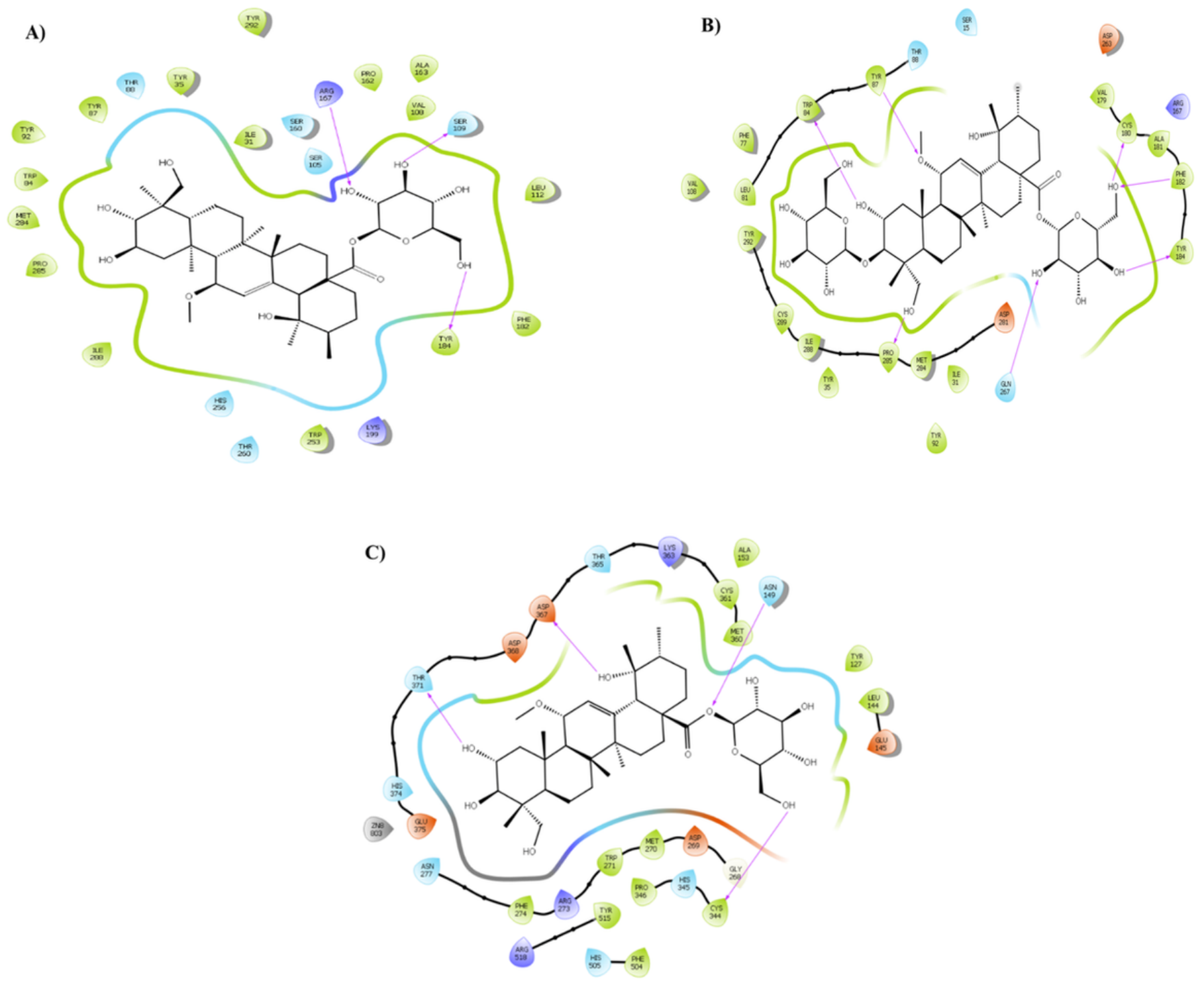

\section{Figure 3}

Presentation of 2D model of interactions between A) compound $\mathbf{5}$ and AT1R (PDB ID: 4ZUD); B) compound 6 and (AT1R) (PDB ID: 4YAY); C) compound 5 and (ACE2) (PDB ID: 1R4L). 

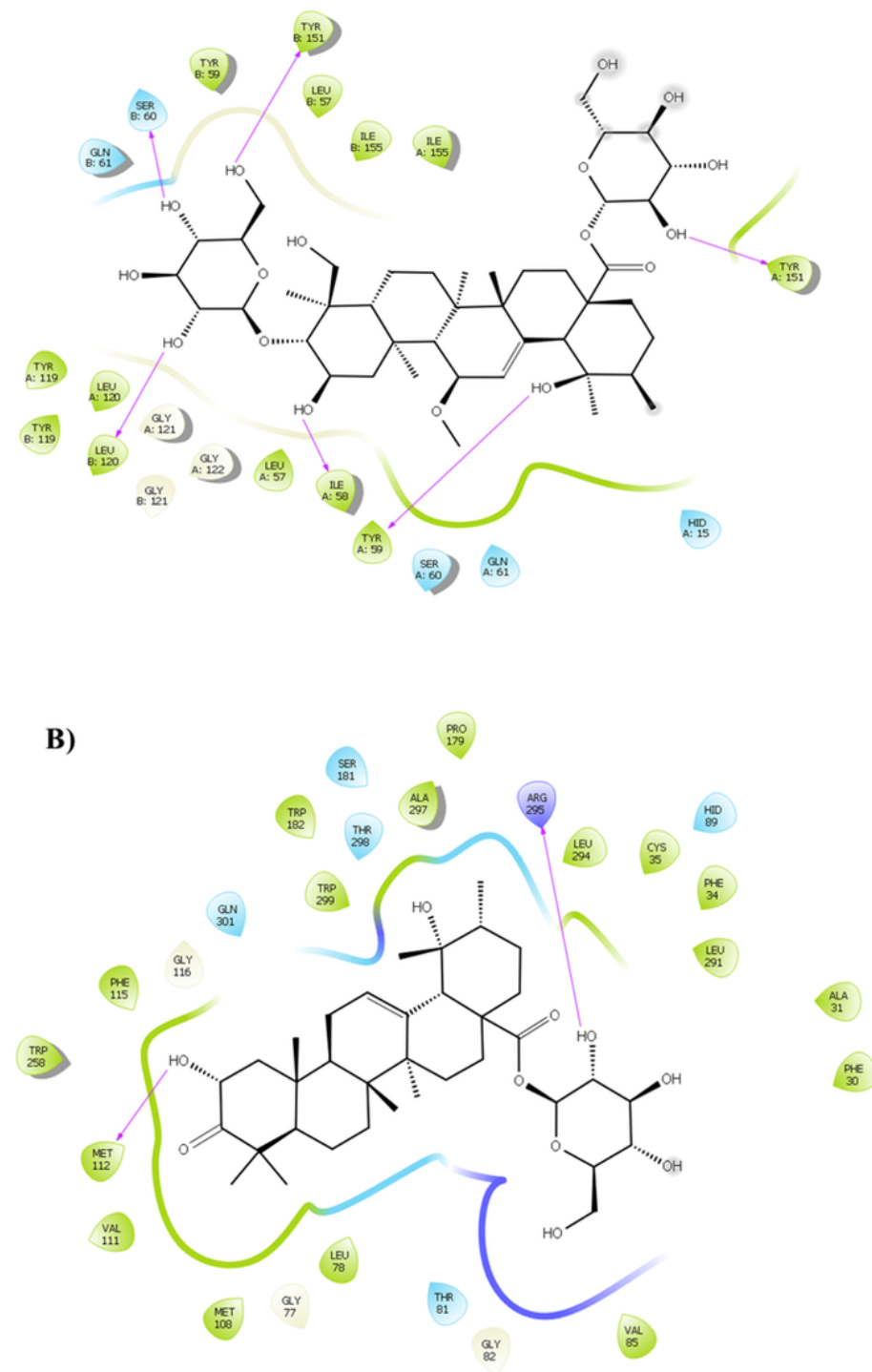

\section{Figure 4}

Presentation of 2D model of interactions between A) compound $\mathbf{6}$ and (TNF-a) (PDB ID: 2AZ5); B) compound $\mathbf{3}$ and (TXA2) (PDB ID: 6IIU). 